\title{
$\mathrm{M}|\mathrm{R}| \mathrm{S}$ Internet Journal Nitride Semiconductor Research
}

\section{High-Performance Solar-Blind AlGaN Schottky Photodiodes}

\author{
Necmi Biyikli ${ }^{1}$, Tolga Kartaloglu ${ }^{1}$, Orhan Aytur ${ }^{1}$, Ibrahim Kimukin $^{2}$ and Ekmel Ozbay ${ }^{2}$ \\ ${ }^{1}$ Bilkent University Dept. of Electrical and Electronics Engineering, \\ ${ }^{2}$ Bilkent University Dept. of Physics,
}

(Received Friday, January 10, 2003; accepted Tuesday, February 25, 2003)

\begin{abstract}
High-performance solar-blind AlGaN-based Schottky photodiodes have been demonstrated. The detectors were fabricated on MOCVD-grown AlGaN/GaN hetero-structures using a microwavecompatible fabrication process. Current-voltage, spectral responsivity, noise, and high-speed characteristics of the detectors were measured and analyzed. Dark currents lower than $1 \mathrm{pA}$ at bias voltages as high as $30 \mathrm{~V}$ were obtained. True solar-blind detection was achieved with a cut-off wavelength lower than $266 \mathrm{~nm}$. A peak device responsivity of $78 \mathrm{~mA} / \mathrm{W}$ at $250 \mathrm{~nm}$ was measured under $15 \mathrm{~V}$ reverse bias. A visible rejection of more than 4 orders of magnitude was observed. The solar-blind photodiodes exhibited noise densities below the measurement setup noise floor of $3 \times 10^{-}$ ${ }^{29} \mathrm{~A}^{2} / \mathrm{Hz}$ around $10 \mathrm{KHz}$. High-speed measurements at the solar-blind wavelength of $267 \mathrm{~nm}$ resulted in 3-dB bandwidths as high as $870 \mathrm{MHz}$.
\end{abstract}

\section{Introduction}

With its wide bandgap and intrinsic visible-blind absorption spectrum, $\mathrm{Al}_{\mathrm{x}} \mathrm{Ga}_{1-\mathrm{x}} \mathrm{N}$ ternary alloy is the most promising material system for high-performance photodetectors operating in the ultraviolet (UV) spectrum [1]. Their cut-off wavelength $\left(\lambda_{\mathrm{c}}\right)$ can be tuned from $365 \mathrm{~nm}$ to $200 \mathrm{~nm}$, which covers the solar-blind spectrum $(\lambda<280 \mathrm{~nm}) \quad$ [2]. Solar-blind detectors play important roles in a variety of military and civil applications including missile plume detection, flame/engine monitoring, chemical/biological agent sensing, and covert space-to-space communications [3]. AlGaNbased solar-blind photodetectors with high responsivity [4] [5], low dark current [6] [7], high solar rejection [8] [9], high bandwidth [10], and high detectivity [11] [12] performance were demonstrated using $\mathrm{p}-\mathrm{i}-\mathrm{n}, \mathrm{MSM}$ and Schottky type detector structures.

Compared with p-i-n photodiodes, AlGaN Schottky photodiodes have several advantages. Growth of $p+$ $\mathrm{AlGaN}$ layers and formation $\mathrm{p}+$ ohmic contacts with low contact resistance are two challenging issues for $\mathrm{p}-\mathrm{i}$ n photodiodes, while Schottky photodiodes do not face these problems. High-quality Schottky and n+ ohmic contacts can be achieved using widely known process techniques. Moreover, since the photocarriers are generated and efficiently collected within the depleted active layer, high-frequency operation of Schottky photodiodes is not affected by minority carrier diffusion [13] [14] [15] [16]. Successful solar-blind operation of AlGaN Schottky photodiodes were demonstrated by several research groups [17] [18]. However, the reported dark current and detectivity performances were poor with respect to AlGaN-based p-i-n and MSM type photodiodes. In terms of high-speed performance, GaN-based visible-blind photodiodes with $3-\mathrm{dB}$ bandwidths in the $\mathrm{GHz}$ regime were successfully demonstrated [19] [20] [21]. Reported AlGaN-based solar-blind detectors had lower bandwidths. A maximum high-speed performance of $100 \mathrm{MHz}$ was reported with an AlGaN MSM photodiode structure [10]. For solar-blind AlGaN Schottky photodiodes the best detector bandwidth demonstrated was below the MHz level [17]. Recently we had demonstrated solar-blind AlGaN Schottky photodiodes with very low dark current and high detectivity [22]. In this paper, we report on the design, fabrication, and characterization of high-performance solar-blind AlGaN Schottky photodiodes with high-speed performance close to the $\mathrm{GHz}$ level.

\section{Experimental Details}

\subsection{Epitaxial Structure Design}

The epitaxial structure of the AlGaN Schottky detector wafer was designed to achieve low cut-off wavelength $\left(\lambda_{\mathrm{c}}<280 \mathrm{~nm}\right)$, high visible rejection, and low dark current. Figure 1 shows the details of the photodiode struc- 
ture. The $\mathrm{Al}_{\mathrm{x}} \mathrm{Ga}_{1-\mathrm{x}} \mathrm{N} / \mathrm{GaN}$ epitaxial layers of our heterojunction Schottky PD wafer were grown by MOCVD on a 2-inch single-side polished (0001) sapphire substrate. The $0.8 \mu \mathrm{m}$ thick undoped AlGaN layer with $38 \% \mathrm{Al}$ concentration was the active absorption region of the detector. The ohmic contacts were formed within the $\mathrm{n}+$ GaN layer. The $0.2 \mu \mathrm{m}$ thick $\mathrm{n}+\mathrm{Al}_{0.38} \mathrm{Ga}_{0.62} \mathrm{~N}$ layer was designed as a diffusion barrier for the holes generated in the $n+G a N$ layer to increase the visible rejection of the detector.

\subsection{Device Fabrication}

Fabrication process of the AlGaN Schottky photodiodes was accomplished in a class-100 clean-room facility using a microwave compatible five mask-level standard semiconductor process [23] [24]. Fabrication started with the formation of $\mathrm{n}+$ ohmic contacts. The ohmic contact regions were etched down to the $\mathrm{n}+\mathrm{GaN}$ ohmic layer using dry etch. Reactive ion etching (RIE) process was utilized under $20 \mathrm{sccm} \mathrm{CCl}_{2} \mathrm{~F}_{2}$ plasma at $100 \mathrm{~W} \mathrm{RF}$ power. Then a $\sim 100 \mathrm{~nm}$ thick Ti/Al contact metal was deposited using thermal evaporation. The metal was lifted off in acetone solution and the samples were annealed at $700{ }^{\circ} \mathrm{C}$ for $30 \mathrm{~s}$ afterwards. Then the device mesas with 30-200 $\mu \mathrm{m}$ diameters were defined using RIE with the same process parameters. Mesa isolation of the devices was completed with a $\sim 1.8 \mu$ m deep etch, down to the undoped GaN layer. This was followed by the evaporation of $\sim 100 \AA$ thick Au film as the Schottky contact metal. Afterwards, a $\sim 100 \mathrm{~nm}$ thick $\mathrm{Si}_{3} \mathrm{~N}_{4}$ layer was deposited using plasma enhanced chemical vapor deposition to passivate the sample surface and protect the thin Schottky contactfilms. In the final step, interconnect pads were formed by a $\sim 0.7 \mu \mathrm{m}$ thick Ti/Au metallization. A schematic cross-section figure of the completed AlGaN Schottky photodiode is shown in Figure 2 .

\subsection{Device Characterization}

After device fabrication, current-voltage (I-V), spectral responsivity, noise, and high-speed characterizations were carried out. All measurements were made onwafer, using a microwave probe station. To observe the electrical diode characteristics and the leakage current, we first performed the I-V measurements. The I-V setup consisted of a Hewlett Packard HP4142B DC parametric measurement instrument, DC probes with triax output and low-noise triax cables. DC current was measured as voltage was applied to the devices.

Spectral responsivity measurements were done using a $175 \mathrm{~W}$ xenon light-source, 1/4 m Digikrom DK240 monochromator, multi-mode UV fiber, DC voltage source, SR830 DSP lock-in amplifier and a Newport model $1830-\mathrm{C}$ calibrated optical power-meter. Xenon lamp output was fed into the monochromator. The monochromator output was chopped and coupled to the fiber using a UV-enhanced focusing lens. The detectors were illuminated by the optical output coming out from the fiber which was calibrated using the calibrated photodetector. The detectors were biased with a DC voltage source upto $50 \mathrm{~V}$, and the resulting photocurrent was measured using the lock-in amplifier.

Low-frequency $(<100 \mathrm{KHz})$ noise characteristics of the solar-blind Schottky detectors were measured with a SR785 dynamic signal analyzer, which measured the fast Fourier transform spectrum of the detector noise. The detectors were reverse biased with a DC voltage source.

Temporal high-frequency measurements were done at the solar-blind wavelength of $267 \mathrm{~nm}$. Ultrafast UV pulses were generated using a laser set-up with two nonlinear crystals. A Coherent Mira 900F model femtosecond mode-locked Ti:sapphire laser was used to generate the pump beam at $800 \mathrm{~nm}$. The pump pulses were produced with $76 \mathrm{MHz}$ repetition rate and 140 fs pulse duration. These pulses were frequency doubled to generate a second harmonic beam at $400 \mathrm{~nm}$ using a $0.5 \mathrm{~mm}$ thick type-I $\beta-\mathrm{BaB} 2 \mathrm{O} 4$ (BBO) crystal. The second harmonic beam and the remaining part of the pump beam were frequency summed to generate a third harmonic output beam at $267 \mathrm{~nm}$ using another type-I BBO crystal with thickness of $0.3 \mathrm{~mm}$. The resulting $267 \mathrm{~nm}$ pulses had pulsewidths below $1 \mathrm{ps}$ and were focused onto the devices using UV-enhanced mirrors and lenses. The detectors were biased using a DC voltage source and a $40 \mathrm{GHz}$ bias-tee. Using $50 \mathrm{GHz}$ microwave probe and cables, the electrical pulses were transferred to a 50 $\mathrm{GHz}$ sampling oscilloscope where the temporal pulse responses were observed.

\section{Measurement Results and Discussion}

The fabricated AlGaN Schottky detectors exhibited low dark currents and high breakdown voltages. Figure 3 shows the I-V curve of a $150 \times 150 \mu \mathrm{m}^{2}$ device with $>50$ $\mathrm{V}$ breakdown voltage. Excellent low-leakage performance was achieved with a dark current below $400 \mathrm{fA}$ under reverse bias voltages as high as $25 \mathrm{~V}$. The dark current fluctuated between 150-400 fA in the 0-25 V reverse bias range (see inset figure). These leakage values correspond to dark current density values of 0.7-1.8 $\mathrm{nA} / \mathrm{cm}^{2}$. The differential resistance $(R=d V / d I)$ of these devices was calculated and their dark impedance was in excess of $10^{13} \Omega$ in the $0-25 \mathrm{~V}$ range. These measurement results correspond to the best I-V performance reported for solar-blind AlGaN Schottky photodiodes. To indicate the performance variation, Figure 4 shows the I-V characteristics of a $200 \mu \mathrm{m}$ diameter photodiode 
fabricated on a different wafer piece. Few pA dark current at $5 \mathrm{~V}$ reverse bias and a breakdown around $20 \mathrm{~V}$ was observed. I-V measurement under UV illumination at $256 \mathrm{~nm}$ showed a clear UV photoresponse when compared with the detector dark current (see inset figure).

Spectral photoresponse measurements of the AlGaN Schottky photodiodes were carried out in the 250-350 nm spectral range. A bias-dependent spectral responsivity with true solar-blind characteristic was observed. Figure 5 shows the measured spectral responsivity of a photodiode with $\sim 20 \mathrm{~V}$ breakdown voltage. The peak responsivity increased with applied reverse bias. The photovoltaic peak responsivity of $36 \mathrm{~mA} / \mathrm{W}$ increased upto $78 \mathrm{~mA} / \mathrm{W}$ under $15 \mathrm{~V}$ reverse bias. At higher reverse biases, photocurrent fluctuations increased and signs of photoconductive gain were observed as the detector operated near the breakdown regime. Peak wavelength of $250 \mathrm{~nm}$ did not change with bias. The peak responsivity value corresponds to a peak quantum efficiency of $39 \%$ at $250 \mathrm{~nm}$. The corresponding spectral quantum efficiency curves are plotted in Figure 6. True solar-blind characteristic was achieved with cut-off wavelengths smaller than $280 \mathrm{~nm}$. The cut-off wavelength changed from $262 \mathrm{~nm}$ to $266 \mathrm{~nm}$ for no bias and $15 \mathrm{~V}$ reverse bias respectively. The device responsivity dropped sharply around $270 \mathrm{~nm}$. A UV/VIS rejection of 3 orders of magnitude was already obtained around 280 $\mathrm{nm}$. For $\lambda>280 \mathrm{~nm}$, the responsivity decay continued with a lower rate and a 4 order of magnitude rejection was achieved before $350 \mathrm{~nm}$. The maximum visible rejection at $350 \mathrm{~nm}$ was recorded as $2.4 \times 10^{4}$ while the detectors were operating in the photovoltaic mode. As applied reverse bias increased, the rejection showed a descending behavior. The measured $\lambda_{c}$ and UV/VIS rejection values correspond to the lowest $\lambda_{c}$ and highest visible rejection reported for solar-blind AlGaN Schottky photodiodes. Table 1 summarizes the spectral responsivity measurement results.

Detector noise characteristics were measured in the $0.1 \mathrm{~Hz}-100 \mathrm{KHz}$ frequency range. Solar-blind AlGaN Schottky photodiodes with low dark current exhibited spectral noise density values below the noise floor of the measurement setup. Noise floor of our setup was around $3 \times 10^{-29} \mathrm{~A}^{2} / \mathrm{Hz}$ for frequencies higher than $1 \mathrm{KHz}$, and increased for lower frequency values. Therefore we were not able to measure the noise density values of our low-leakage devices. To understand the dominant noise mechanism and its bias dependence, we measured a device with high leakage (few $\mu \mathrm{A}$ dark current at $5 \mathrm{~V}$, breakdown at $\sim 14 \mathrm{~V}$ ). The detectors displayed 1/f-noise characteristic with noise densities proportional to reverse bias. Figure 7 shows the dark current noise power density values measured at $1 \mathrm{~Hz}$ as a function of applied reverse bias voltage. With increasing bias from 0 $\mathrm{V}$ to $10 \mathrm{~V}$, the noise density increased by more than 4 orders of magnitude.

Time-domain high-speed characterization of the fabricated solar-blind Schottky photodiodes resulted in very fast pulse responses with high $3-\mathrm{dB}$ bandwidths. The detector pulse response was bias dependent. Faster pulses were obtained for higher reverse bias values as the thick n- AlGaN absorption layer was fully depleted under high reverse bias voltages. As the bias tee limit was $16 \mathrm{~V}$, we were not able to increase the bias voltage above this limit. The fastest pulse response was measured with an $80 \mu \mathrm{m}$ diameter device (Figure 8). Under $15 \mathrm{~V}$ reverse bias, it produced a pulse response with a very fast rise time of $12 \mathrm{ps,}$, and a full-width-at-halfmaximum (FWHM) of 216 ps. Using FFT, the corresponding 3-dB bandwidth of the detector was calculated as $870 \mathrm{MHz}$. Pulse responses with narrower pulsewidths were also measured, but their calculated 3-dB bandwidth was lower due to longer decay parts. Figure 9 shows such a response of a $30 \mu \mathrm{m}$ diameter solar-blind detector with 13 ps rise time, 74 ps FWHM, and 300 $\mathrm{MHz} 3-\mathrm{dB}$ bandwidth.

To analyze this unexpected longer decay time for a smaller diode area, curve fitting with exponential decay functions were applied to the measured pulse responses shown in Figure 8 and Figure 9. A simple first order exponential fit with a single time constant could not be achieved. Instead, both responses were fitted well with second order exponential decay functions, i.e. with a sum of two exponential decay functions with two different time constants. The fit for $80 \mu \mathrm{m}$ diameter device response had time constants of $157 \mathrm{ps}$ and $2.85 \mathrm{~ns}$, while the $30 \mu \mathrm{m}$ diameter device response fit exhibited time constants of 120 ps and 5.45 ns. These time constants agree with our bandwidth calculations: The response with the shorter FWHM but lower 3-dB bandwidth (30 $\mu \mathrm{m}$ diameter diode) had a shorter initial decay time constant along with a longer subsequent decay time constant. The reverse conditions were valid for the other device response giving rise to a longer FWHM but higher 3-dB bandwidth. The physical reason for the multi-exponential relaxation mechanism was not clear. Evenmore, the initial decay time constants were much longer than the RC time constants of 4 ps and 27 ps for $30 \mu \mathrm{m}$ and $80 \mu \mathrm{m}$ device respectively. These results convinced us that mechanisms other than $\mathrm{RC}$ and transit time limitations were responsible for the decay part of the high-speed response of these solar-blind detectors. We postulate that the long and multi-exponential decay times are related to issues such as carrier trapping effect in AlGaN layers, carrier diffusion component originating from low field regions close to the center of the mesa, and growth/process related effects. A detailed 
study on the relaxation mechanisms of solar-blind AlGaN PDs will be made in the near future.

Although there were exceptions, as discussed above, in general, an inverse proportionality between device area and detector bandwidth was observed. FFT curves of 4 pulse responses from detectors with different device areas are plotted in Figure 10. 3-dB bandwidths of 220, 280, 510, and $780 \mathrm{MHz}$ were obtained for devices with $200,150,100$, and $60 \mu \mathrm{m}$ diameter respectively. These results correspond to the best high-speed performance reported for any type of solar-blind photodetectors.

\section{Summary and Conclusions}

High-performance solar-blind AlGaN Schottky photodiodes have been successfully designed, fabricated and tested. The solar-blind Schottky detectors displayed dark current densities as low as $7 \times 10^{-10} \mathrm{~A} / \mathrm{cm}^{2}$ under reverse biases as high as $25 \mathrm{~V}$. A bias dependent spectral responsivity was observed with a maximum peak responsivity of $78 \mathrm{~mA} / \mathrm{W}$ at $250 \mathrm{~nm}$. The corresponding peak quantum efficiency obtained from these devices was $39 \%$. True solar-blind detection was demonstrated with a sharp cut-off at $266 \mathrm{~nm}$. The AlGaN Schottky photodiodes exhibited over 4 orders of magnitude visible rejection within $100 \mathrm{~nm}$, with a maximum rejection of $2.4 \times 10^{4}$ at zero bias. Low frequency noise was $1 / \mathrm{f}$ limited with noise power densities below the measurement setup noise floor of $3 \times 10^{-29} \mathrm{~A}^{2} / \mathrm{Hz}$. Time-domain high-frequency measurements resulted in very short rise times and 3-dB bandwidths as high as $870 \mathrm{MHz}$ were achieved. The recorded values for dark current, cut-off wavelength, visible rejection, and high-speed measurements correspond to the best detector performance results reported for solar-blind AlGaN Schottky photodiodes.

\section{ACKNOWLEDGMENTS}

This work was supported by NATO Grant No. SfP971970, Turkish Department of Defense Grant No. KOBRA-002, and FUSAM-03.

\section{REFERENCES}

[1] M. Razeghi, A. Rogalski , J. Appl. Phys. 79, 7433-7473 (1996).

[2] P. Schreiber, T. Dang, G. Smith, T. Pickenpaugh, P. Gehred, C. Litton, Proc. SPIE 3629, 230 (1999).

[3] J. C. Carrano, T. Li, P. A. Grudowski, R. D. Dupuis, J. C. Campbell, IEEE Circuits \& Devices Mag. 15, 15 (1999).
[4] D. Walker, V. Jumar, K. Mi, P. Kung, X. H. Zhang, M. Razeghi, Appl. Phys. Lett. 76, 403 (2000).

[5] M. M. Wong, U. Chowdhury, C. J. Collins, B. Yang, J. C. Denyszyn, K. S. Kim, J. C. Campbell, R. D. Dupuis, Phys. Stat. Sol. A 188, 333 (2001).

[6] B. Yang, D. J. H. Lambert, T. Li, C. J. Collins, M. M. Wong, U. Chowdhury, R. D. Dupuis, J. C. Campbell, Electron. Lett. 36, 1866 (2000).

[7] V. V. Kuryatkov, H. Temkin, J. C. Campbell, R. D. Dupuis, Appl. Phys. Lett. 78, 3340 (2001).

[8] P. Sandvik, K. Mi, F. Shahedipour, R. McClintock, A. Yasan, P. Kung, M. Razeghi, J. Cryst. Growth 231, 366 (2001).

[9] A. Hirano, C. Pernot, M. Iwaya, T. Detchprohm, H. Amano, I. Akasaki, Phys. Stat. Sol. A 188, 293 (2001).

[10] T. Li, D. J. H. Lambert, A. L. Beck, C. J. Collins, B. Yang, M. M. Wong, U. Chowdhury, R. D. Dupuis, J. C. Campbell, Electron. Lett. 36, 1581 (2000).

[11] C. J. Collins, U. Chowdhury, M. M. Wong, B. Yang, A. L. Beck, R. D. Dupuis, J. C. Campbell, Appl. Phys. Lett. 80, 3754 (2002).

[12] C. J. Collins, U. Chowdhury, M. M. Wong, B. Yang, A. L. Beck, R. D. Dupuis, J. C. Campbell, Electron. Lett. 38, 824 (2002).

[13] S. Y. Wang, D. M. Bloom, Electron. Lett. 19, 554 (1983).

[14] D. G. Parker, P. G. Say, A. M. Hansom, Electron. Lett. 23, 527 (1987).

[15] B. M. Onat, M. Gokkavas, E. Ozbay, E. Ata, E. Towe, M. S. Unlu, IEEE Photonics Technol. Lett. 10, 707 (1998).

[16] N. Biyikli, I. Kimukin, O. Aytur, M. Gokkavas, M. S. Unlu, E. Ozbay, IEEE Photonics Technol. Lett. 13, 705 (2001).

[17] A. Osinsky, S. Gangopadhyay, B. W. Lim, M. Z. Anwar, M. A. Khan, D. Kuksenkov, H. Tempkin, Appl. Phys. Lett. 72, 742 (1998).

[18] S. L. Rumyantsev, N. Pala, M. S. Shur, R. Gaska, M. E. Levinshtein, V. Adivarahan, J. Yang, G. Simin, M. Asif Khan, Appl. Phys. Lett. 79, 866 (2001).

[19] J. C. Carrano, T. Li, D. L. Brown, P. A. Grudowski, C. J. Eiting, R. D. Dupuis, J. C. Campbell, Appl. Phys. Lett. 73, 2405 (1998).

[20] J. C. Carrano, T. Li, D. L. Brown, P. A. Grudowski, C. J. Eiting, R. D. Dupuis, J. C. Campbell, Electron. Lett. 34, 1779 (1998).

[21] N. Biyikli, T. Kartaloglu, O. Aytur, I. Kimukin, E. Ozbay, Appl. Phys. Lett. 79, 2838 (2001).

[22] N. Biyikli, O. Aytur, I. Kimukin, T. Tut, E. Ozbay, Appl. Phys. Lett. 81, 3272 (2002).

[23] E. Ozbay, M. S. Islam, B. M. Onat, M. Gokkavas, O. Aytur, G. Tuttle, E. Towe, R. H. Henderson, M. S. Unlu, IEEE Photonics Technol. Lett. 9, 672 (1997).

[24] I. Kimukin, E. Ozbay, N. Biyikli, T. Kartaloglu, O. Aytur, S. Unlu, G. Tuttle, Appl. Phys. Lett. 77, 3890 (2000). 
FIGURES

\begin{tabular}{|cc|}
\hline $0.8 \mu \mathrm{m}$ & $\mathrm{N}-\mathrm{AIGaN}(38 \%)$ \\
\hline $0.2 \mu \mathrm{m} \quad \mathrm{N}+\mathrm{AIGaN}(38 \%)$ \\
\hline $0.6 \mu \mathrm{m} \quad \mathrm{N}+\mathrm{GaN}$ \\
\hline $0.5 \mu \mathrm{m} \quad$ undoped GaN \\
\hline Thin AIN nucleation layer \\
\hline Sapphire Substrate \\
\hline
\end{tabular}

Figure 1. Epitaxial layer structure of solar-blind AlGaN Schottky photodiode wafer.

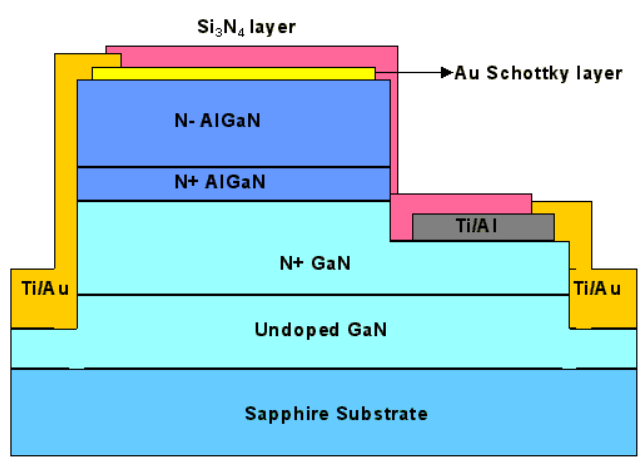

Figure 2. Cross-section schematic of the fabricated AlGaN Schottky photodiode.

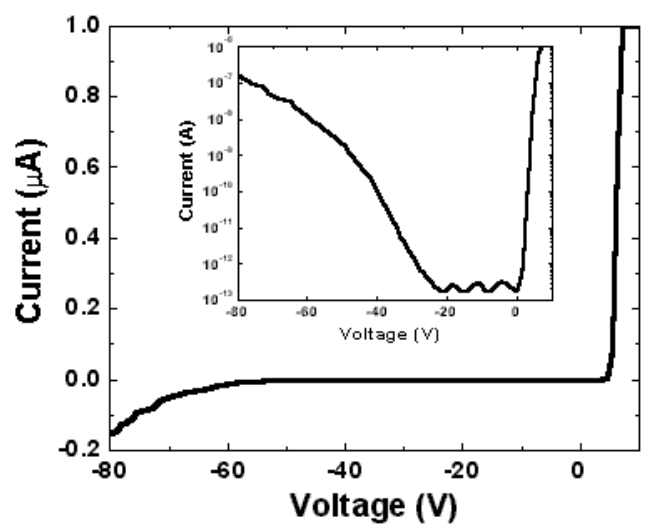

Figure 3. I-V characteristics of a $150 \times 150 \mu \mathrm{m} 2$ solar-blind Schottky photodiode. Inset shows the measured curve in logarithmic scale.

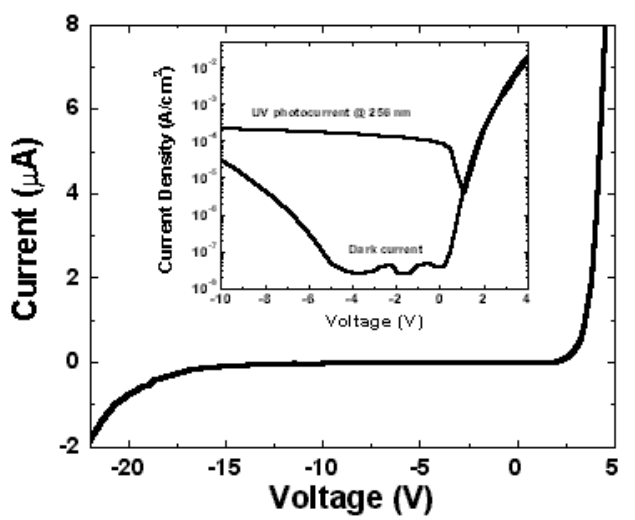

Figure 4. I-V measurement curve of a $200 \mu \mathrm{m}$ diameter Schottky detector. Inset shows dark current versus UV photocurrent at $256 \mathrm{~nm}$.

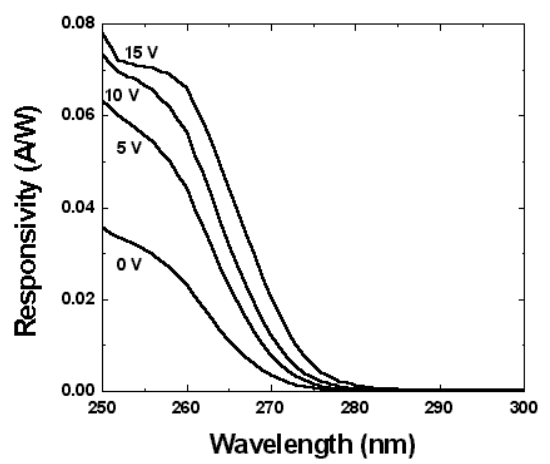

Figure 5. Spectral responsivity of the AlGaN Schottky photodiodes. A peak responsvity of $78 \mathrm{~mA} / \mathrm{W}$ at $250 \mathrm{~nm}$ was obtained under $15 \mathrm{~V}$ reverse bias.

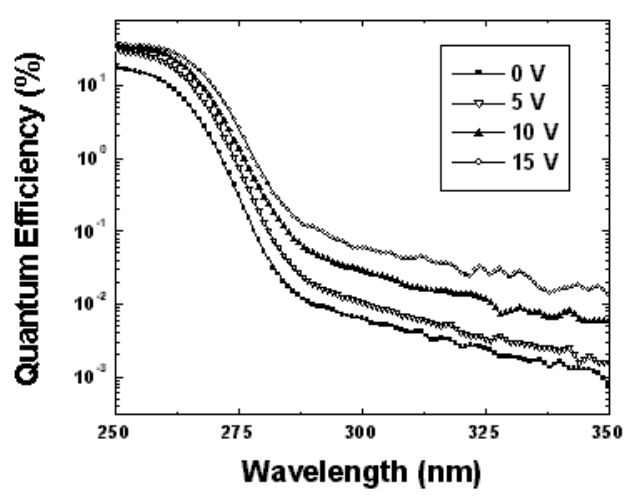

Figure 6. Bias-dependent spectral quantum efficiency curves of the solar-blind Schottky detector. A peak efficiency of 39\% at $250 \mathrm{~nm}$ with a solar-blind cut-off at $266 \mathrm{~nm}$ was measured at 15 $\mathrm{V}$. 


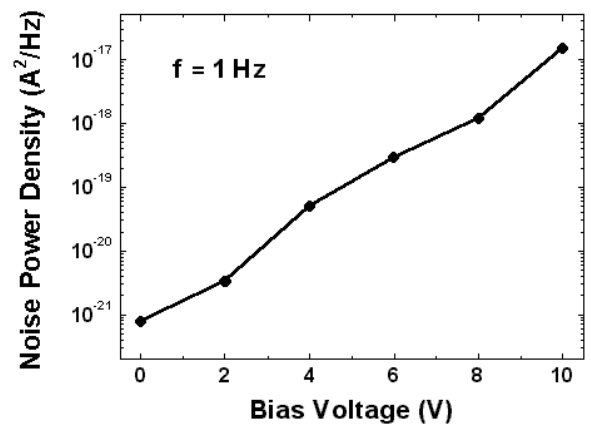

Figure 7. Dark current noise power density of an $80 \mu \mathrm{m}$ diameter high leakage Schottky photodiode at $1 \mathrm{~Hz}$ as a function of reverse bias.

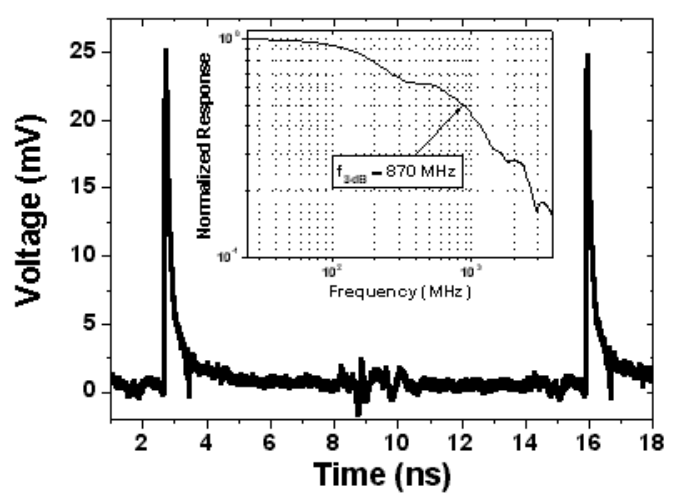

Figure 8. Best pulse response measured with an $80 \mu \mathrm{m}$ diameter device. Inset shows the FFT of temporal data. The AlGaN Schottky photodiode performed a 3-dB bandwidth of $870 \mathrm{MHz}$.

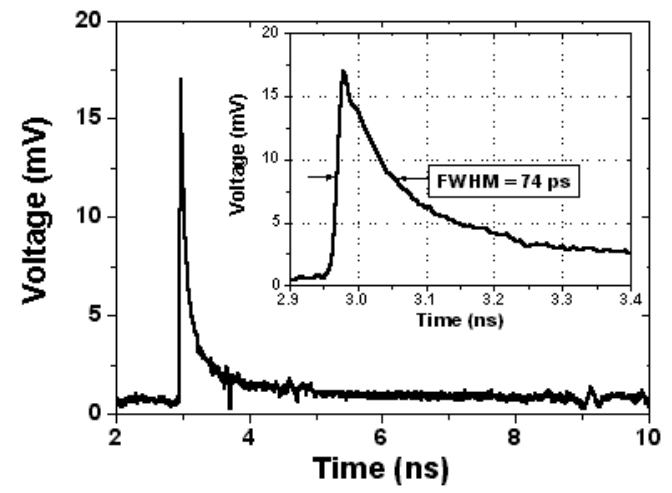

Figure 9. Pulse response of a $30 \mu \mathrm{m}$ diameter solar-blind detector with 74 ps FWHM and $300 \mathrm{MHz} 3-\mathrm{dB}$ bandwidth. Inset shows the zoomed plot of the pulse response.

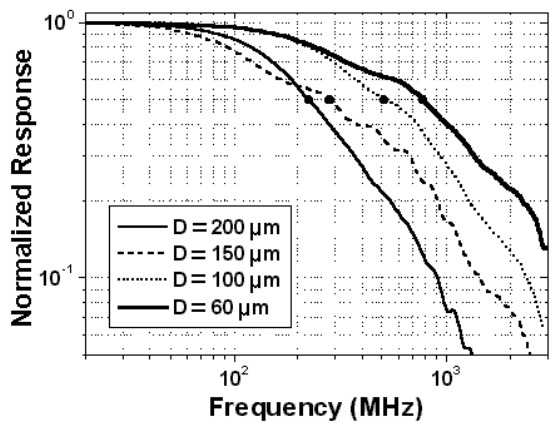

Figure 10. FFT curves of pulse responses from Schottky detectors with different device areas. 3-dB bandwidths of 220, 280, 510, and $780 \mathrm{MHz}$ were obtained with decreasing device area.

\section{TABLES}

Table 1. Spectral photoresponse measurement results obtained for solar-blind AlGaN Schottky photodiodes.

\begin{tabular}{|c|l|c|c|c|}
\hline Bias Voltage & $\begin{array}{l}\text { Peak } \\
\text { Responsivit } \\
\mathbf{y}\end{array}$ & $\begin{array}{l}\text { Peak } \\
\text { Efficiency }\end{array}$ & $\begin{array}{l}\text { Cut-off } \\
\text { wavelength }\end{array}$ & $\begin{array}{l}\text { UV/VIS } \\
\text { rejection }\end{array}$ \\
\hline $0 \mathrm{~V}$ & $\begin{array}{c}36 \mathrm{~mA} / \mathrm{W} @ \\
250 \mathrm{~nm}\end{array}$ & $\begin{array}{c}17.7 \% @ \\
250 \mathrm{~nm}\end{array}$ & $262 \mathrm{~nm}$ & $2.4 \times 10^{4}$ \\
\hline $5 \mathrm{~V}$ & $\begin{array}{c}63 \mathrm{~mA} / \mathrm{W} @ \\
250 \mathrm{~nm}\end{array}$ & $\begin{array}{c}31.5 \% @ \\
250 \mathrm{~nm}\end{array}$ & $263 \mathrm{~nm}$ & $2.0 \times 10^{4}$ \\
\hline $10 \mathrm{~V}$ & $\begin{array}{c}74 \mathrm{~mA} / \mathrm{W} @ \\
250 \mathrm{~nm}\end{array}$ & $\begin{array}{c}36.4 \% @ \\
250 \mathrm{~nm}\end{array}$ & $264 \mathrm{~nm}$ & $6.4 \times 10^{3}$ \\
\hline $15 \mathrm{~V}$ & $\begin{array}{c}78 \mathrm{~mA} / \mathrm{W} @ \\
250 \mathrm{~nm}\end{array}$ & $\begin{array}{c}38.7 \% @ \\
250 \mathrm{~nm}\end{array}$ & $266 \mathrm{~nm}$ & $2.8 \times 10^{3}$ \\
\hline
\end{tabular}

